DOI: https://doi.org/10.24867/04BE12Djuric

\title{
PRORAČUN REŽIMA ELEKTROENERGETSKIH SISTEMA SA KVAROM U FAZNOM DOMENU
}

\section{POWER SYSTEMS SHORT CIRCUIT CALCULATION IN PHASE DOMAIN}

\author{
Mirko Đurić, Fakultet tehničkih nauka, Novi Sad
}

\begin{abstract}
Oblast - ELEKTROTEHNIKA I RAČUNARSTVO
Kratak sadržaj - U ovom radu prikazan je postupak za formiranje matematičkih modela elemenata elektroenergetskih sistema u faznom domenu, njihovu integracija $u$ jedinstveni model $i$ proračun režima sa kratkim spojem elektroenergetskih sistema. Proračuni su izvršeni u programskom jeziku Fortran.
\end{abstract}

Ključne reči: Modelovanje elemenata elektroenergetskih sistema, režim sa kratkim spojem, fazni domen

Abstract - This paper presents the procedure for creating mathematical models of the elements of electric power systems in the phase domain, their integration into a unique model and the calculation of the regime with a short circuit of the electric power systems. All calculations are realized in Fortran programming language.

Keywords: Modeling Elements of Power Systems, Short Circuit Regime, Phase Domain

\section{UVOD}

Proračun režima elektroenergetskog sistema (EES) sa kvarom je, uz proračun tokova snaga, najznačajniji problem koji se razmatra u domenu (kvazi)stacionarne elektroenergetike [1-4].

Postupci za proračun režima EES sa kvarom se mogu razlikovati u zavisnosti od krajnjeg cilja proračuna koji se provodi. Uobičajeno, cilj proračuna je podešenje relejne zaštite, mehaničko i termičko dimenzionisanja opreme, sigurnost sa aspekta opreme, itd. U tom slučaju proračun režima EES sa kvarom se sprovoditi samo za fazni deo sistema. Ukoliko je cilj proračuna dimenzionisanje sistema uzemljenja, proračun napona koraka i dodira, odnosno sigurnost sa aspekta ljudi, itd. tada se osim faznog dela mora obuhvatiti i sistem uzemljenja.

Generalno, metode za proračun režima EES sa kvarom mogu da se podele na metode bazirane na kompleksnim analitičkim izrazima i numeričke metode. Metode bazirane na analitičkim izrazima karakterišu relativno jednostavni matematički modeli. One su razvijene na osnovu većeg broja aproksimacija i samim tim imaju umanjenu tačnost rezultata i značajna ograničenje praktične primene.

Numeričke metode imaju znatno manje aproksimacija i pogodne su za obradu problema velikih dimenzija. Samim ove metode imaju znatno veće mogućnosti i njihovom primenom se dobijaju znatno tačniji rezultati. Njihova praktična primena zahteva primenu računara.

\section{NAPOMENA:}

Ovaj rad proistekao je iz master rada čiji je mentor dr Goran Švenda, red.prof.
Proračuni režima EES sa kvarom mogu se vršiti u domenu simetričnih komponenti i u faznom domenu. Proračuni u domenu simetričnih komponenti su karakteristični za uravnotežene EES, kada je od interesa proračun samo režima u faznom delu sistema. Proračuni u faznom domenu karakteristični za neuravnotežene EES, odnosno kada je od interesa režim faznog i sistema uzemljenja.

\section{PARCIJALNI MATEMATIČKI MODELI ELEMENATA EES}

Veličina i složenost realnih EES kao i veliki broj efekata koji se u njima ispoljavaju za posledicu imaju velike dimenzije matematičkih modela kojima se opisuju. Ovi matematički modeli se, radi jednostavnijeg generisanja $i$ obrade, zasnivaju na metodi potencijala čvorova, odnosno na odgovarajućim matricama admitansi nezavisnih čvorova $\underline{Y}_{\text {BUS. }}$ Tri osnovne osobine matrica admitansi su: trivijalno se generišu, simetrične su i retke [1,5]. Treba naglasiti da se ove tri osobine ispoljavaju u električnim kolima u kojima nema kontrolisanih izvora (uzemljeni delovi EES spregnuti efektom blizine, elektromagnetski spregnuti provodnici i idealni transformatori).

U cilju modelovanja EES sa kvarom, moguće je definisati pojedinačne matematičke modele elemenata (podsistema) EES. Razmatrani EES moguće je dekomponovati na podsistem uzemljivača, podsistem provodnika, podsistem transformatora i podsistem elektroenergetskog okruženja između kojih postoje isključivo galvanske veze. Uticaji kontrolisanih izvora, u okviru podsistema, ekvivalentirani su uticajem admitantnih grana. Nakon formiranja matematičkih modela pojedinačnih podsistema, moguće je te parcijalne modele integrisati u jedinstven matematički model EES jedinstvenu matricu admitansi celokupnih EES.

\subsection{Podsistem uzemljivača}

Podsistem uzemljivača, sa $N_{U Z}$ uzemljivača [6], prikazan je na slici 1. Uzemljivači su predstavljeni sa svojim međusobnim uticajima - efekat blizine. Sa 1,2..., $N_{U Z}$ su naznačene tačke u kojima su uzemljivači galvanski spojeni sa elementima EES-a.

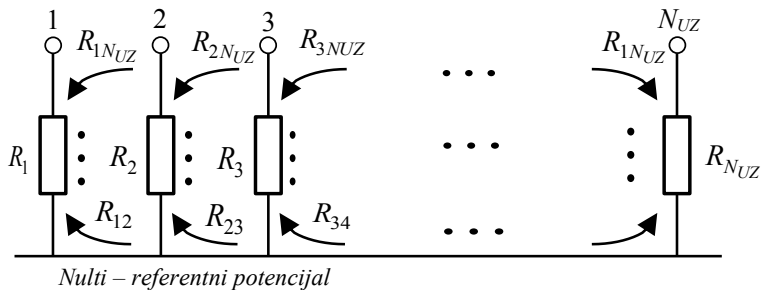

Slika 1. Podsistem uzemljivača koji se sastoji od $N$ uzemljivača 
Efekat blizine predstavljen je sopstvenim i međusobnim otpornostima uzemljivača kao mera uticaja struje kvara kroz uzemljivač na vrednosti sopstvenih potencijala i potencijala ostalih uzemljivača, ali i na raspodelu struje kvara unutar podsistema uzemljivača.

Zemlja predstavlja čist aktivni otpor, a celo uzemljenje sa zemljovodnim provodnikom i uzemljivačem ima vrlo malu induktivnost za učestanost od $50 \mathrm{~Hz}$, tako da je svaki uzemljivač predstavljen svojom aktivnom otpornošću $R_{1}, R_{2}, . ., R_{N u z}$. Dakle, sopstvene i međusobne impedanse uzemljivača sadrže samo realne delove. Matematički model za podsistem uzemljivača sa slike 1 može se napisati u impedantnoj formi:

$$
\left[\underline{\mathbf{V}}_{U Z}\right]_{N \times 1}=\left[\underline{\mathbf{Z}}_{U Z}\right]_{N \times N} \cdot\left[\underline{\mathbf{I}}_{U Z}\right]_{N \times 1},
$$

i admitantnoj formi:

$$
\begin{aligned}
& {\left[\underline{\mathbf{I}}_{U Z}\right]_{N \times 1}=\left[\underline{\mathbf{Y}}_{U Z}\right]_{N \times N} \cdot\left[\underline{\mathbf{V}}_{U Z}\right]_{N \times 1}} \\
& \left(\left[\underline{\mathbf{Y}}_{U Z}\right]_{N \times N}=\left[\underline{\mathbf{Z}}_{U Z}\right]_{N \times N}^{-1}\right)
\end{aligned}
$$

\subsection{Podsistem provodnika}

Na slici 2 prikazana je blok šema četvorožičnog nadzemnog voda (uvažavajući uticaj povratnog puta kroz zemlju) [6].

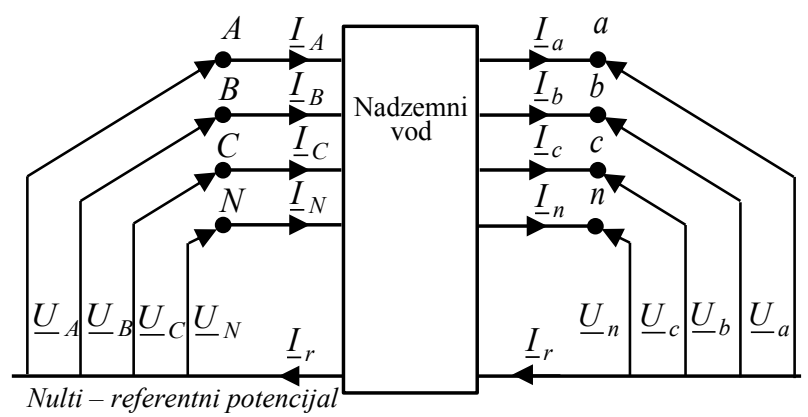

Slika 2. Blok šema nadzemnog voda

Kao inicijalnu tačku posmatranja prilikom izvođenja matematičkog modela nadzemnog voda, može se uzeti jednačina za padove napona duž provodnika, iskazanu u impedantnoj formi:

$$
\left[\Delta \underline{\mathbf{U}}_{\mathrm{Pr}}\right]_{4 \times 1}=\left[\underline{\mathbf{Z}}_{\mathrm{Pr}}\right]_{4 \times 4} \cdot\left[\underline{\mathbf{i}}_{\mathrm{Pr}}\right]_{4 \times 1} .
$$

Relacija (3) predstavlja odnos struja duž provodnika i pada napona na provodnicima (razlike potencijala sa krajeva provodnika). U cilju formiranja matematičkog modela, u skladu sa metodom potencijala čvorova, vektor kolona padova napona duž provodnika, mora se iskazati kao razlika potencijala sa početka i kraja provodnika, tj.:

$$
\left[\Delta \underline{\mathbf{U}}_{\mathrm{Pr}}\right]_{4 \times 1}=\left[\underline{\mathbf{V}}_{\text {pocetak }}\right]_{4 \times 1}-\left[\underline{\mathbf{V}}_{\text {kraj }}\right]_{4 \times 1} .
$$

Posmatrano u admitantnoj formi, jednačina za padove napona duž provodnika dobija sledeći oblik:

$$
\left[\underline{\mathbf{i}}_{\operatorname{Pr}}\right]=\left[\underline{\mathbf{Y}}_{\operatorname{Pr}}\right] \cdot\left[\Delta \underline{\mathbf{U}}_{\operatorname{Pr}}\right], \quad\left[\underline{\mathbf{Y}}_{\mathrm{Pr}}\right]=\left[\underline{\mathbf{Z}}_{\mathrm{Pr}}\right]^{-1},
$$

pri čemu je sa $\left[Y_{\mathrm{Pr}}\right]_{4 \times 4}$ naznačena matrica sopstvenih $\mathrm{i}$ međusobnih admitansi provodnika nadzemnog voda.

Ako se za referentni smer struja provodnika usvoji smer od početka prema kraju provodnika, onda su struje injektirane u čvorove na početku provodnika jednake strujama provodnika sa pozitivnim predznakom, a struje injektirane u čvorove na kraju provodnika negativnim vrednostima struja provodnika:

$$
\begin{aligned}
& {\left[\underline{\mathbf{I}}_{\text {pocetak }}\right]=\left[\underline{\mathbf{i}}_{p r}\right],} \\
& {\left[\underline{\mathbf{I}}_{k r a j}\right]=-\left[\underline{\mathbf{i}}_{p r}\right] .}
\end{aligned}
$$

$\mathrm{Na}$ osnovu relaciju (5), (6) i (7) može se formirati matematički model podsistema provodnika u skladu sa metodom potencijala čvorova:

$\left[\begin{array}{l}\underline{\mathbf{I}}_{\text {pocetak }} \\ \underline{\mathbf{I}}_{\text {kraj }}\end{array}\right]=\left[\begin{array}{cc}\underline{\mathbf{Y}}_{p r} & -\underline{\mathbf{Y}}_{p r} \\ -\underline{\mathbf{Y}}_{p r} & \underline{\mathbf{Y}}_{p r}\end{array}\right] \cdot\left[\begin{array}{l}\underline{\mathbf{V}}_{\text {pocetak }} \\ \underline{\mathbf{V}}_{k r a j}\end{array}\right]=\left[\underline{\mathbf{Y}}_{2 p r}\right] \cdot\left[\begin{array}{l}\underline{\mathbf{V}}_{\text {pocetak }} \\ \underline{\mathbf{V}}_{k r a j}\end{array}\right]$

Sopstvene i međusobne vrednosti parametara provodnika mogu se izračunati na osnovu Karsonovih i Polačekovih formule [2]. Jednostavni Karsonovi izrazi za proračun podužne vrednosti sopstvenih i međusobnih impedansi provodnika, korišćeni u ovom radu su $[3,6]$ :

$$
\begin{gathered}
\underline{z}_{i i}=r_{z}+r_{p i}+j 0.1445 \cdot \log _{10} \frac{D_{e}}{a_{e i}}, \\
\underline{z}_{i j}=r_{z}+j 0.1445 \cdot \log _{10} \frac{D_{e}}{d_{i j}} .
\end{gathered}
$$

\subsection{Podsistem transformatora}

Blok šema trofaznog dvonamotajnog transformatora [6] prikazana je na slici 3 .

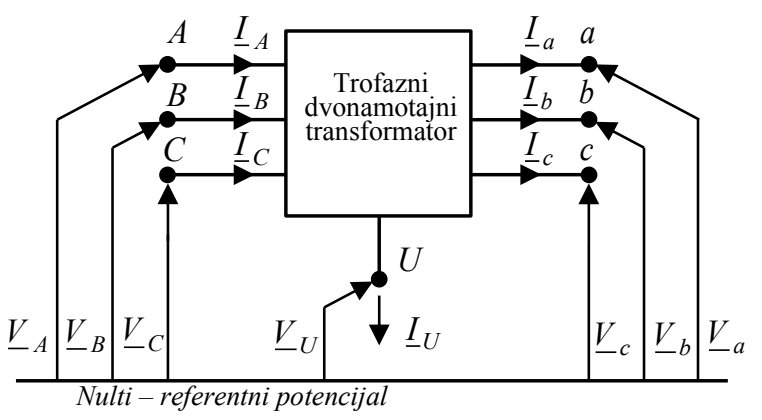

Slika 3. Blok šema trofaznog dvonamotajnog transformatora

Razmatrani transformator ima ukupno sedam tačaka za galvansko povezivanje sa ostatkom sistema. Sa $A, B i C$, su naznačeni krajevi visokonaponske (VN) strane, a sa $a$, $b i c$ krajevi niskonaponske (NN) strane transformatora. Priključak za uzemljenje transformatora, povezivanje sa podsistemom uzemljenja, naznačen je sa $U$.

Matematički model dvonamotajnog transformatora u domenu simetričnih komponenti, napisan u formi koja odgovara metodu potencijala čvorova, glasi:

$$
\left[\underline{\mathbf{I}}_{T 2}^{\text {dio }}\right]_{7 \times 1}=\left[\underline{\mathbf{Y}}_{T 2}^{\text {dio }}\right]_{7 \times 7} \cdot\left[\underline{\mathbf{V}}_{T 2}^{\text {dio }}\right]_{7 \times 1} .
$$

U cilju dobijanja konačnog matematičkog modela transformatora u faznom domenu, potrebno je izvršiti transformaciju matematičkog modela napisanog $\mathrm{u}$ domenu simetričnih komponenti. U tu svrhu koriste se matrica transformacija (domena simetričnih komponentni $\mathrm{u}$ fazni domen) $[\underline{A}]$ i njena inverzna matrica $[\underline{A}]^{-1}[1,5,7,9]$, odnosno proširena matrica transformacije $\left[\underline{A}_{2}\right]$ i njena inverzna matrica $\left[\underline{A}_{2}\right]^{-1}$.

Matematički model transformatora u faznom domenu: 


$$
\left[\underline{\mathbf{I}}_{T 2}\right]_{7 \times 1}=\left[\underline{\mathbf{Y}}_{T 2}\right]_{7 \times 7} \cdot\left[\underline{\mathbf{V}}_{T 2}\right]_{7 \times 1} .
$$

\subsection{Podsistem elektroenergetskog okruženja}

Podsistem elektroenergetskog okruženja predstavlja ceo EES iz koga je potisnut sistem od interesa. Elektroenergetsko okruženje se može predstaviti kao „crna kutija” koja sadrži sve elemente EES osim elemenata sistema od interesa, a sa sistemom od interesa je povezan isključivo galvanski, preko graničnih čvorova.

Model elektroenergetskog okruženja se može definisati uz pomoć snage jednopolnog i tropolnog kratkog spoja, kao i napona u graničnim čvorovima u kojima se izvode potrebni proračuni.

Matematički model podsistema elektroenergetskog okruženja (sa $N_{E}$ čvorova) u domenu simetričnih komponenti opisan je sledećom relacijom:

$\left[\underline{\mathbf{I}}_{E E O}^{\text {dio }}\right]_{N_{E} \times 1}=\left[\underline{\mathbf{Y}}_{E E O}^{\text {dio }}\right]_{N_{E} \times N_{E}} \cdot\left[\underline{\mathbf{V}}_{E E O}^{\text {dio }}\right]_{N_{E} \times 1}$.

Matematički model podsistema elektroenergetskog okruženja u faznom domenu ima izgled:

$$
\left[\underline{\mathbf{I}}_{E E O}\right]_{3 N_{E} \times 1}=\left[\underline{\mathbf{Y}}_{E E O}\right]_{3 N_{E} \times 3 N_{E}} \cdot\left[\underline{\mathbf{V}}_{E E O}\right]_{3 N_{E} \times 1} \text {. }
$$

\section{INTEGRACIJA PARCIJALNIH MATEMATIČ- KIH MODELA}

Nakon određivanja pojedinačnih matematičkih modela sistema, potrebno je izvršiti njihovu integraciju u cilju formiranja konačnog matematičkog modela EES.

U cilju formiranja matematičkog modela EES potrebno je definisati jedinstvenu numeraciju svih čvorova. Ukupan broj čvorova definiše dimenziju celokupnog sistema, odnosno broj jednačina preko kojih se može odrediti režim EES-a.

Jedinstvena numeracija svih čvorova omogućava da se za svaki podsistem, formira matrica admitansi čije su dimenzija jednake ukupnom broju čvorova celokupnog EES. Integracijom četiri matrice admitansi, koje su nezavisno formirane za četiri podsistema, jednostavno se formira matrica admitansi EES. Integracija matrica admitansi podsistema se svodi na sabiranjem elemenata tih matrica.

Konačno, matematički model EES sa N čvorova, glasi:

$$
\left[\underline{\mathbf{I}}_{E E S}\right]_{N \times 1}=\left[\underline{\mathbf{Y}}_{E E S}\right]_{N \times N} \cdot\left[\underline{\mathbf{V}}_{E E S}\right]_{N \times 1} .
$$

\section{PRORAČUN REŽIMA EES SA KVAROM}

Postupak za proračuna režima EES sa kratkim spojem se, generalno, sastoji iz četiri dekompozicije [3,5,7]:

- dekompozicija režima s kratkim spojem na poznati režim pre kratkog spoja i režim jednog izvedenog trofaznog delta kola $(\Delta$-kola $)$ - delta režim $(\Delta$-režim $)-I$ dekompozicija;

- dekompozicija $\Delta$-režima na naizmeničnu i jednosmernu komponentu - II dekompozicija;

- dekompozicija naizmenične komponente $\Delta$-kola na tri vremenske sekvence suptranzitni, tranzitni i ustaljeni period (režim) - III dekompozicija;
- transformacija naizmeničnih režima $\Delta$-kola u sve tri vremenske sekvence iz domena faznih u domen simetričnih komponenti - $I V$ dekompozicija.

U ovom radu proračun režima EES sa kratkim spojem se bazira na prvoj dekompoziciji, odnosno na proračun režima $\Delta$-kola $-\Delta$-režima. Motiv za tretman režima EES sa kratkim spojem u skladu sa ostale tri dekompozicije ogleda se u postojanju naizmeničnih mašina u EES, koje diktiraju promenu amplitude ma koje veličine naizmenične komponente režima $\Delta$-kola u vremenu.

\subsection{Proračun režima $\Delta$-kola}

U slučaju dekompozicije kola sa kvarom režim pre kvara je poznat, dok se režim $\Delta$-kola računa, tako što se idealni naponski generator umetne samo na mestu kvara, dok se svi ostali izvori pasiviziraju.

$\mathrm{Na}$ slici 4 prikazan je deo EES na kome je nastupio jednofazni zemljospoj [6].

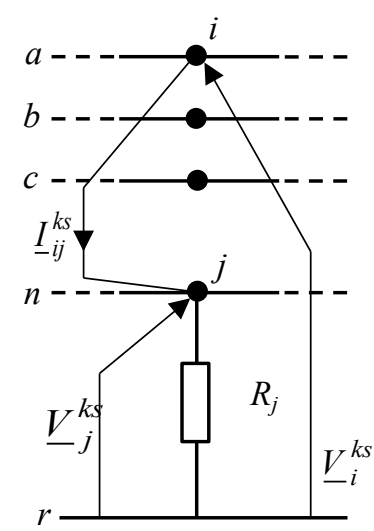

Slika 4. - Deo EES na kome je nastupio jednofazni zemljospoj

U ovom radu razmatra se metalni kratak spoj (kratak spoj bez luka, koji se predstavlja kao kvar preko impedanse). U skladu sa tim, grana sa strujom kratkog spoja je bezimpedantna grana.

U granu sa kvarom se insertuju dva jednaka idealna naponska izvora vezana u opoziciju (zajedno kao jedan nulti idealni naponski izvor), slika 5 a.

Napon insertovanog idealnog naponskog izvora $\underline{V}_{i}^{P}$ sa slike 5a jednak je naponu na mestu kvara pre kvara. Ako se na ovom mestu, a u skladu sa prvom dekompozicijom, kolo sa slike 5a dekomponuje na dva kola, i to tako da se u prvom kolu zadrži idealni naponski izvor usmeren od zemlje, odnosno tačke $j$, ka sistemu, a u drugom kolu idealni naponski izvor, koji je usmeren od sistema ka zemlji, odnosno tački $j$.

To drugo kolo, nad kojim će se vršiti proračuni od interesa naziva se $\Delta$-kolo i prikazano je na slici 5 b.

Naponi tačaka $i$ i $j$ u ekvivalentnom, $\Delta$-kolu, sa slike $5 \mathrm{~b}$, naznačeni su sa $\underline{V}_{i} \mathrm{i} \underline{V}_{j}$, respektivno.

Struje injektirane u čvorove $i \mathrm{i} j$, naznačene su sa $\underline{I}_{i}$ i $\underline{I}_{j}$, respektivno, dok je struja kratkog spoja na mestu kratkog spoja naznačena sa $\underline{I}_{i j}$. 


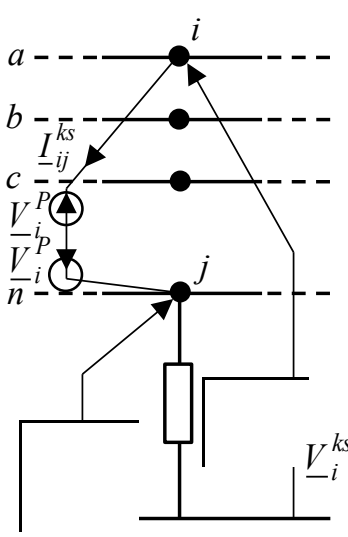

a)

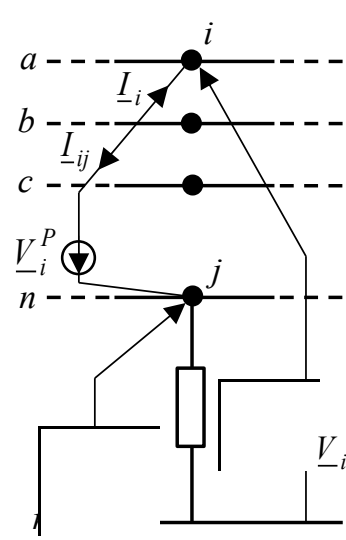

b)
Slika 5. Sistem sa kratkim spojem u tački i a) sa insertovanim parom idealnih naponskih izvora i b) 4-kolo na kojem je simuliran jednofazni zemljospoj

Na osnovu slike, sledi:

$$
\begin{aligned}
& \underline{V}_{i}=\underline{V}_{j}-\underline{V}_{i}^{P}, \\
& \underline{I}_{i}=-\underline{I}_{j} \quad\left(=-\underline{I}_{i j}\right),
\end{aligned}
$$

Konačno, matematički model $\Delta$-kola, u matričnoj formi, raspregnuti izraz (15):

$$
\left[\begin{array}{c}
\underline{V}_{1} \\
\vdots \\
\underline{V}_{i} \\
\vdots \\
\underline{V}_{j} \\
\vdots \\
\underline{V}_{N}
\end{array}\right]=\left[\begin{array}{ccccccc}
\underline{Z}_{11} & \cdots & \underline{Z}_{1 i} & \cdots & \underline{Z}_{1 j} & \cdots & \underline{Z}_{1 N} \\
\vdots & & \vdots & & \vdots & & \vdots \\
\underline{Z}_{1 i} & \cdots & \underline{Z}_{i i} & \cdots & \underline{Z}_{i j} & \cdots & \underline{Z}_{i N} \\
\vdots & & \vdots & & \vdots & & \vdots \\
\underline{Z}_{j 1} & \cdots & \underline{Z}_{j i} & \cdots & \underline{Z}_{j j} & \cdots & \underline{Z}_{j N} \\
\vdots & & \vdots & & \vdots & & \vdots \\
\underline{Z}_{N 1} & \cdots & \underline{Z}_{N i} & \cdots & \underline{Z}_{N j} & \cdots & \underline{Z}_{N N}
\end{array}\right] \cdot\left[\begin{array}{c}
0 \\
\vdots \\
\underline{I}_{i} \\
\vdots \\
\underline{I}_{j} \\
\vdots \\
0
\end{array}\right]
$$

Izraz (18) zapisan u skraćenoj formi:

$$
[\underline{\mathbf{V}}]_{N \times 1}=\left[\underline{\mathbf{Z}}_{E E S}\right]_{N \times N} \cdot[\underline{\mathbf{I}}]_{N \times 1} \text {. }
$$

Treba uočiti da su jedine nenulte vrednosti struja, struja injektiranih u čvorove, struje kvara injektirane u čvorove zahvaćene kvarom. Na osnovu izraza (16), (17) i (18), mogu se odrediti vrednosti struja na mestu kvara (za kratak spoj između tačaka $i \mathrm{i} j$ ):

$$
\underline{I}_{i}=-\underline{I}_{j}=\frac{-\underline{V}_{i}^{P}}{\underline{Z}_{i i}-\underline{Z}_{i j}-\underline{Z}_{j i}+\underline{Z}_{j j}}=\frac{-\underline{V}_{i}^{P}}{\underline{Z}_{E K V}}\left(=-\underline{I}_{i j}\right) .
$$

Za poznate vrednosti struja kvara, koje su injektirane $\mathrm{u}$ čvorove $i$ i $j$, na osnovu izraza (18), mogu se odrediti vrednosti potencijala $\Delta$-kola za sve čvorove EES. Za poznate vrednosti potencijala svih čvorova, jednoznačno je definisan režim celokupnog $\Delta$-kola. Superpozicijom režima $\Delta$-kola i kola pre kvara dobija se režima kola sa kvarom.

\section{ZAKLJUČAK}

U ovom radu prikazan je postupak za formiranje matematičkog modela EES u faznom domenu, i na osnovu njega proračun režima EES sa kvarom. Postupak modelovanja je pojednostavljen podelom sistema na četiri podsistema između kojih postoje isključivo galvanske veze. $\mathrm{Za}$ svaki podsistem formiran je poseban nezavisan model, a modeli su razvijeni u faznom domenu, u admitantnoj formi. Integracijom parcijalnih modela formiran je model EES sa kvarom.

Primenom prikazanog postupka izbegnute su uobičajene aproksimacije pri modelovanju i proračunima struje kvara, raspodele struje kvara $\mathrm{i}$ raspodele potencijala režima EES sa kvarom. Neke od njih su:

- uticaj galvanske veze krajeva provodnika električne zaštite i uzemljivača transformatora;

- sistem uzemljenja transformatorske stanice i stubova i zvezdišta transformatora nisu na nultom potencijalu.

Time je prikazan model pogodan za proračun (dimenzionisanje) uzemljivača postrojenja, zaštitnih užadi, električne zaštite, napona koraka i dodira itd. Istovremeno prikazani model može da bude merodavan za vrednovanje tačnosti i verodostojnosti rezultata dobijenih korišćenjem uprošćenih matematičkih modela i za verifikaciju (ne)opravdanosti uvođenja aproksimacija na tačnost proračuna režima sa kvarom.

\section{LITERATURA}

[1] V.C.Strezoski: Analiza elektroenergetskih sistema, Fakultet tehničkih nauka, Novi Sad, 2007.

[2] G.S.Švenda: Osnovi elektroenergetike: matematički modeli i proračuni, Fakultet tehničkih nauka, Novi Sad, 2007.

[3] A.R.Bergen, V.Vittal: Power Systems Analysis, PrenticeHall Inc, New Jersey, USA, 2000.

[4] J.J.Grainger, W.D.Stevensen: Power Systems Analysis, McGraw-Hill, Inc., New Jersey, USA, 1994.

[5] Vladimir C. Strezoski, Dragan S. Popović: Proračuni stacionarnih režima elektroenergetskih sistema, Fakultet tehničkih nauka, Novi Sad, 2008.

[6] G.S.Švenda: Specijalizovani softveri u elektroenergetici, materijal sa predavanja, Fakultet tehničkih nauka, Novi Sad, 2015.

[7] N.D.Tleis: Power Systems Modelling and Fault Analysis: Theory and Practice, Newnes Power Engineering, Elsevier Ltd, Oxford, UK, 2008.

[8] K.Kasaš-Lažetić: Modelovanje impedanse zemlje kao povratnog provodnika, doktorska disertacija, Fakultet tehničkih nauka, Novi Sad, 2015.

[9] W.D.Stevenson: Elements of Power System Analysis, Fourth Edition, McGraw-Hill, New York, USA, 1982.

\section{Kratka biografija:}

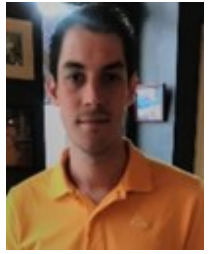

Mirko Đurić rođen je u Valjevu 1989. god. Srednju tehničku školu (Elektrotehničar računara) završio je 2008. god. u Valjevu. Diplomski rad na Fakultetu tehničkih nauka iz oblasti Elektrotehnike i računarstva Elektroenergetski sistemi odbranio je 2015. god. Iste godine upisao se na master studije. 